\section{Physics research}

SIR - "Basic physics in doldrums" (Nature 300, 571; 1982) summarized the findings of a study, "Trends in Research Output and Funding"' (Physics Today, p.9 November 1982) which I conducted in collaboration with Harold Weinstock, Francis Narin and Samuel R. Reisher. While the Nature article provides excellent coverage of a number of the salient findings of our study, the opening sentence attributes to us a judgement which we were careful not to make, that "Basic physics research in the United States is declining in quality compared with Europe ..." In point of fact we applied no quality measures in our study. Rather, we compiled data on (1) the numbers (quantities) of papers published in Physical Review Letters and in Applied Physics Letters by various performing sectors and (2) the numbers (quantities) of papers attributed to various funding sources. The findings led us to comment that "We view these trends with concern and believe they correspond to a reduction - in real terms - of US activity in basic physics since the late 1960s". The emphasis here is on the reduction in the quantity (not quality) of activity.

The Nature article also asserts that "The ONR study speculates that this dramatic shift in foreign contributions might be caused by editorial policy". In actuality, referring to Physical Review Letters, we commented only that "The total number of papers published per year by all sources rises until 1968 and thereafter remains relatively constant at approximately 1,000 papers per year, presumably a consequence of editorial policy". Although the presumption in the last phrase proved to be incorrect, our statement contains no speculation that editorial policy might have caused a shift in foreign contributions.

It is recognized that varying interpretations of our data are possible. For readers who might wish to draw their own conclusions from the original data I shall be pleased to provide, on request, copies of a more comprehensive version of the report than that which appeared in Physics Today.

Office of Naval Research,

TED G. BERLINCOURT Arlington, Virginia, USA

\section{Xenology disputed}

SIR - In proposing the word xenology to collectively describe extraterrestrial studies, R.A. Freitas Jr (Nature 13 January, p.106) notes that Reynolds' used this word to describe the study of xenon isotopes, but claims that this use of the word xenology "has negligible currency in the literature". We disagree.

Reynolds'defines xenology as "the detailed study of the abundance of Xe isotopes evolved from meteorites ..." The word now is used also for all terrestrial and extraterrestrial (including the Moon and Mars) studies of xenon isotopes ${ }^{2-5}$. The element xenon has nine stable isotopes that can have a variety of origins. As noted by Pepin": "The cornerstone of xenology is the experimental observation that $\mathrm{Xe}$ isotopic ratios differ in significant and complex ways among naturally occurring samples". There are more than 20 research groups in at least eight countries that measure and use xenon isotopic abundances in studies of terrestrial and extraterrestrial samples. Many of the scientists in these groups frequently use the word xenology. The word Xenologie is in the title of a German article ${ }^{3}$; the English abstract uses xenology. A recent paper ${ }^{4}$ is entitled "Terrestrial xenology". A subchapter of a new book" is "Unsolved problems in xenology".

The failure of $\mathrm{Mr}$ Freitas to find xenology as a subject category is not surprising, as many words formed by adding -ology to a noun are filed under the category of the noun itself. Thus works on xenology are found under xenon. Having clearly refuted Mr Freitas' claim that xenology has "negligible currency", and shown that it is well established in referring to studies of xenon isotopes, we urge that xenology not be used for any other field.

ROBERT C. REEDY

FRIEDRICH BEGEMANN LUDOLF SCHULTZ

JANE CRABB

Max-Planck-Institut für Chemie, D-6500 Mainz, FRG

I. Reynolds, J.H. J. geophys. Res. 68, 2939-2956 (1963)

2. Pepin, R. O. \& Phinney, D. Moon and Planets (submitted).

3. Hintenberger, H. Naturwissenschaften 59, 285-291 (1972)

. Staudacher, T. \& Allègre, C.J. Earth planet. Sci. Letl. 60 389-406 (1982).

Kuroda, P.K. The Origin of the Chemical Elements (Springer, Berlin, 1982).

SIR - Robert A. Freitas Jr's letter (Nature 13 January, p.106) is an eloquent plea for a name we do not need. While a universally accepted collective term could be useful for studies on extraterrestrial life, given their largely common factual and theoretical bases, attempts to bring some or all of nonsolar planetary physics, pre-biotic geology and other disciplines into this category is merely verbal colonialism, and does not reflect the organization of knowledge or research effort. The term "xenology" is unwanted and misleading, implying a grand unification absent in fact.

It also fails to suggest "extraterrestrial studies", rather meaning "studies of the unexplained/unusual/strange" through common technical usage of the "xen" root. "Xenology" could thus be replaced by "science" in most contexts.

WILliam Bains

Stanford University Medical Center. California, USA

\section{Down to Earth}

SIR - May 1 as organizer of the Royal Society discussion meeting on the Earth's core, protest mildly at your comment
(Nature 23 December 1982, p.681) on the proceedings". You say "Shockingly it makes no mention of Ramsey's theory

" that the core is not iron or iron alloy but a metallic phase of the silicates of the Earth's mantle induced by the high pressure. You are less than fair to the distinguished geophysicists who contributed to this part who may well have taken to heart Professor Lyttleton's recent admonition to geophysicists (in a review ${ }^{2}$ on comets . . .) to adhere to Occam's razor which, as he so clearly expounds, "enjoins our scientists to include no hypotheses not absolutely required ....".

Neither experimental nor theoretical work at high pressure gives any evidence that such a phase change would occur at the pressure in the Earth's core, or that the density jump would be as large as is observed, or that the phase change pressure will change in the way Professor Lyttleton requires in his Earth contraction model. Nor is an Earth contraction hypothesis relevant to explaining tectonics on the Earth as we now know it looks as a result of palaeomagnetic, geological and geophysical studies over the last quarter of a century.

Nor is there any reason now from work on the Sun and carbonaceous chondritic materials to doubt (as there once was) that the cosmic abundance of iron is such that an iron core is reasonable. Had you read the Royal Society publication, instead of being shocked by it, you would have noticed that a correlation between the irregular fluctuations in the length of the day and the relative rotation of the core and mantle, as measured by the geomagnetic westward drift, means that interchange of angular momentum between core and mantle is occurring on the time scale of decades (by electromagnetic coupling) and may very well do so on much longer time scales. I explain that there is some archaeomagnetic evidence for this and that it would explain the acceleration over the past 2,500 years, as inferred from the ancient eclipse data, recently put on a satisfactory basis by F.R. Stephenson.

School of Physics,

University of Newcastle upon Tyne, UK

1. Phil. Trans. R. Soc. 306, 1-208 (1982).

. Brandt, J.C. \& Chapman, R.D. J. Br. astron. Ass. 200-202 (1982).

ONLY Lyttleton carries a torch for the Earthcontraction hypothesis, while the simplest version of Ramsey's theory (silicate to silicate phase transition) is, as Professor Runcorn says, ruled out by observation. But in his introduction to the Royal Society meeting, Dr J.A. Jacobs said " . . .we know more about the interior of Jupiter than we do about that of the Earth. I should like to see more experimental work at high pressures and temperatures simultaneously . particular attention should be paid to phase transitions in mantle materials and to the nature of the core-mantle boundary ...', I agree, and would not be surprised if the result were the discovery that the mantle-core boundary is less a manifestation of chemical differentiation than is now assumed. - Editor, Nature 